\title{
The quality of research with real-world informationaging
}

\section{La calidad de la investigación con información del mundo real.}

\section{Mauricio Palacios Gómez}

\author{
Editor en Jefe, Revista Colombia Médica, Universidad del Valle. Cali, Colombia.,
}

Most of the medical practice has not been proven by controlled clinical trials, and there are no plans to conduct such trials in order to decrease clinician uncertainty. This happens partly due to the difficulty of making designs with scientific and ethical validity, the costs of this type of research and the time required to generate results, which can be several years. Clinical trials do not have the capability to generate information that allows to make decisions in some sectors of clinical care and public health, such as when an epidemic occurs. Therefore, medical science is based on observational studies, past practices and therapeutic tradition ${ }^{1}$

Observation of clinical data that have defined a clinical behavior precedes the clinical trial. The knowledge about scurvy, the fact that this pathology is considered a nutritional deficiency and its treatment with citrus fruits, originated thanks to the collection of clinical data on sailors, soldiers and prisoners of the British Crown in the 18th and 19th centuries ${ }^{2}$. This clinical information, which was collected uniformly and served to produce new knowledge, is what is now known as Real World Data (RWD). A modern definition of RWD would be one that talks about data obtained by any non-interventionist methodology that is collected prospectively and retrospectively from observations of routine clinical practice, and which comes from various sources including data from patients, doctors, hospitals, payers, social data, etc ${ }^{3}$.

Although the leading role of RWD was replaced in the mid-20th century by the controlled clinical trial that offered greater scientific rigidity, in recent decades RWD have regained vigour due to technology that allows the storage and retrieval of large volumes of information about many of aspects of clinical care.

The current contribution to this way of acquiring knowledge is the evaluation method called Real Word Evidence (RWE). The RWE is the compilation of all the information routinely collected on patients from clinical systems into an understandable and homogeneously analysable data set (big data) facilitated by the technology, which reflects the reality of treatment in the best possible and comparable way ${ }^{4}$. RWE is derived from the RWD analysis.

The progression of the contribution of RWE research has been greater in areas of epidemiological surveillance, that collects real-time information on emerging diseases ${ }^{5}$, and in pharmacovigilance, that uses it to monitor and quantify adverse drug and therapeutic effects ${ }^{6}$. The use of RWE is now proposed to approve therapeutic indications for medications ${ }^{7}$, and the use of this information in single-arm clinical trials to define drug efficacy in orphan diseases has recently been accepted ${ }^{8,9}$.

The greatest strength of RWE studies is their external validity. Despite including controlled clinical trials to make their recommendations, $44 \%$ of Cochrane Reviews concluded that "the evidence is insufficient for clinical practice" ${ }^{10}$. This happens because clinical trials only represent small, homogeneous populations and are not generalizable to most of the study population ${ }^{11}$. 


\section{Conflicts of interest: \\ None}

\section{Corresponding autor:}

Mauricio Palacios Gómez, Editor en jefe, Revista Colombia Médica, Universidad del Valle. Cali, Colombia. E-mail:

mauricio.palacios@correounivalle.edu.co
Producing quality RWE research requires an adequate design that takes into account the major limitations of observational studies: confounding, selection, and information biases, especially when seeking causality ${ }^{7,12}$. The design and planning of RWE studies are essential to produce science, because the large amount of information that these databases have can overwhelm the researcher and make them believe that they are contributing scientifically when they are not contributing new knowledge ${ }^{13}$.

The editor's mission in RWE research evaluations is to achieve the principles of the scientific process: discovery, transparency, and replicability ${ }^{14,15}$. To guarantee the rigor and methodological transparency that supports the research with databases, the RECORD (Reporting of studies Conducted using Observational Routinely-collected health Data) and RECORD-PE (pharmacovigilance) guides were created, which are an expansion of the STROBE guidelines that take into account specific problems of research results using routinely collected health data ${ }^{15,16}$. The purpose of these guidelines is to promote the quality of RWD sources and RWE studies publications, so that the findings of these investigations are taken into account in clinical practice, systematic reviews and evaluations of health technologies ${ }^{17}$. As their authors warn, these are guidelines for the presentation of scientific reports and should not be taken as guidelines for designing research with RWD.

Colombia Médica adheres to the RECORD and RECORD-PE statements in the journal's instructions and will encourage the use of these resources by our authors, peer reviewers and associate editors, with the conviction of publishing the best version of their manuscripts.

The publication of these guides is a great help to publishers due to the growing demand for RWE research publication requests. But it's not enough; the ethical evaluation of these investigations also requires that the ethics committees evolve, because the analyses cannot be considered from the point of view of ethics in traditional research. The right to autonomy is very difficult to protect and if great efforts are made to avoid traceability, the quality of data will be affected. Transparency should emerge as an important value in researchers, both in the clarity of the elaboration of the research question (especially in exploratory studies) and in the availability of data to be reviewed by other researchers ${ }^{18}$.

\section{References}

1. Frieden TR. Evidence for Health Decision Making - Beyond Randomized, Controlled Trials. Drazen JM, Harrington DP, McMurray JJV, Ware JH, Woodcock J, editors. N Engl J Med [Internet]. 2017 Aug 3 [cited 2020 Mar 18];377(5):465-75. Available from: http://www.nejm.org/doi/10.1056/NEJMra1614394

2. Harrison M. Scurvy on sea and land: Political economy and natural history, c. 1780-c. 1850. J Marit Res. 2013 May 1;15(1):7-25.

3. Makady A, de Boer A, Hillege H, Klungel O, Goettsch W. What Is Real-World Data? A Review of Definitions Based on Literature and Stakeholder Interviews. Value Heal. 2017 Jul 1;20(7):858-65.

4. Maissenhaelter BE, Woolmore AL, Schlag PM. Real-world evidence research based on big data: Motivation—challenges—success factors. Onkologe. 2018 Nov 1;24(Suppl 2):91-8.

5. Briere JB, Bowrin K, Taieb V, Millier A, Toumi M, Coleman C. Meta-analyses using real-world data to generate clinical and epidemiological evidence: a systematic literature review of existing recommendations. Vol. 34, Current Medical Research and Opinion. Taylor and Francis Ltd; 2018. p. 2125-30.

6. Moore N, Blin P, Droz C. Pharmacoepidemiology. In: Handbook of Experimental Pharmacology. Springer; 2019. p. 433-51. 
7. Yuan H, Ali MS, Brouwer ES, Girman CJ, Guo JJ, Lund JL, et al. Real-World Evidence: What It Is and What It Can Tell Us According to the International Society for Pharmacoepidemiology (ISPE) Comparative Effectiveness Research (CER) Special Interest Group (SIG). Vol. 104, Clinical Pharmacology and Therapeutics. Nature Publishing Group; 2018. p. 239-41.

8. Lee D, Brereton N, Dhanasiri S, Kulasekararaj A. The Role of Real-World Evidence in UK Reimbursement: Case Study of Lenalidomide in Myelodysplastic Syndrome Deletion 5q. PharmacoEconomics - Open. 2019 Sep 1;3(3):351-8.

9. Schuller Y, Biegstraaten M, Hollak CEM, Klümpen HJ, Gispen-De Wied CC, Stoyanova-Beninska V. Oncologic orphan drugs approved in the EU - Do clinical trial data correspond with real-world effectiveness? Orphanet J Rare Dis. 2018 Nov 28;13(1).

10. Villas Boas PJF, Spagnuolo RS, Kamegasawa A, Braz LG, Polachini Do Valle A, Jorge EC, et al. Systematic reviews showed insufficient evidence for clinical practice in 2004: What about in 2011? the next appeal for the evidence-based medicine age [Internet]. Vol. 19, Journal of Evaluation in Clinical Practice. 2013 [cited 2020 Mar 18]. p. 633-7. Available from: http://www.ncbi.nlm.nih.gov/pubmed/22747638

11. Courtright K. POINT: Do Randomized Controlled Trials Ignore Needed Patient Populations? Yes [Internet]. Vol. 149, Chest. Elsevier Inc; 2016 [cited 2020 Mar 18]. p. 1128-30. Available from: http://www. ncbi.nlm.nih.gov/pubmed/27157212

12. Schneeweiss S. Learning from big health care data. N Engl J Med. 2014;370(23):2161-3.

13. Khosla S, White R, Medina J, Ouwens M, Emmas C, Koder T, et al. Real world evidence (RWE) - a disruptive innovation or the quiet evolution of medical evidence generation? F1000Research. 2018;7:111.

14. Glasziou P, Altman DG, Bossuyt P, Boutron I, Clarke M, Julious S, et al. Reducing waste from incomplete or unusable reports of biomedical research. Vol. 383, The Lancet. Lancet Publishing Group; 2014. p. 267-76.

15. Benchimol El, Smeeth L, Guttmann A, Harron K, Moher D, Peteresen I, et al. The REporting of studies Conducted using Observational Routinely-collected health Data (RECORD) Statement. PLoS Med. $2015 ; 12(10)$.

16. Langan SM, Schmidt SA, Wing K, Ehrenstein V, Nicholls SG, Filion KB, et al. The reporting of studies conducted using observational routinely collected health data statement for pharmacoepidemiology (RECORD-PE). BMJ [Internet]. 2018 Nov 14 [cited 2019 May 27];363:k3532. Available from: https://www. bmj.com/content/363/bmj.k3532.full

17. Oehrlein EM, Graff JS, Perfetto EM, Mullins CD, Dubois RW, Anyanwu C, et al. Peer-reviewed journal editors' views on real-world evidence. Int J Technol Assess Health Care [Internet]. 2018 Jan [cited 2020 Mar 19];34(1):111-9. Available from: http://www.ncbi.nlm.nih.gov/pubmed/29415784

18. Lipworth W, Mason PH, Kerridge I, loannidis JPA. Ethics and Epistemology in Big Data Research. In: Journal of Bioethical Inquiry. Springer Netherlands; 2017. p. 489-500. 